\title{
The Fetal Pillow: A new option for delivering the deeply impacted fetal head
}

\author{
For laboring women with a prolonged second stage \\ who require a cesarean delivery, use of the Fetal Pillow \\ will decrease traumatic extensions of the uterine incision \\ and facilitate delivery of the fetal head
}

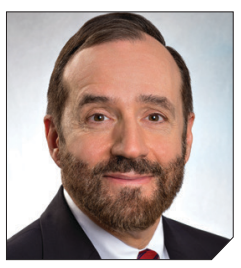

\author{
Robert L. Barbieri, MD \\ Editor in Chief, OBG MANAGEMENT \\ Chair, Obstetrics and Gynecology \\ Brigham and Women's Hospital \\ Boston, Massachusetts \\ Kate Macy Ladd Professor of Obstetrics, \\ Gynecology and Reproductive Biology \\ Harvard Medical School
}

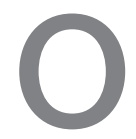

bstetricians know that a cesarean delivery (CD) for a woman with a prolonged second stage and a fetal head deeply impacted in the pelvis is challenging. In this situation, extensions of the uterine incision commonly occur, resulting in prolonged operative time and increased blood loss. Even more harrowing is the inability to deliver the fetal head, necessitating emergency assistance from other clinicians. In this situation, interventions that may be helpful include:

- extend or T the uterine incision

- enlist the aid of a clinician to push up on the fetal head with a vaginal hand (FIGURE 1)

- reverse breech extraction (FIGURE 2), and

- vaginal insertion of a Fetal Pillow prior to starting the delivery.

Evidence from clinical trials indicates that reverse breech extraction or insertion of a Fetal Pillow result in the best clinical outcomes.

\section{Reverse breech extraction vs the push technique}

Although the data are limited, most studies report that compared with pushing up with a vaginal hand (as shown in Figure 1), the reverse breech extraction technique (as shown in Figure 2) is associated with a reduction in extensions of the uterine incision, reduced blood loss, and reduced operative time. ${ }^{1}$ In a randomized trial, 108 women with obstructed labor undergoing CD in the second stage were randomly assigned to reverse breech extraction or pushing up with a vaginal hand. ${ }^{2}$ Following the uterine incision, the reverse breech extraction technique is performed by immediately reaching into the upper uterus and grasping the lower portion of the fetal leg and applying gentle traction on the leg until the second leg appeared. The lower legs are then pulled out of the uterus. Standard breech delivery maneuvers are used to deliver the shoulders and head. In the trial, compared with the push technique, reverse breech extraction was associated with fewer extensions of the uterine incision ( $30 \%$ vs $11 \% ; P<.05$ ), less blood loss ( $899 \mathrm{~mL}$ vs 1,257 mL; $P<.001)$, and shorter operative time (56 min vs $89 \mathrm{~min}, P<.001$ ). Fetal injury was similar with the push and breech extraction techniques (6\% and $7 \%$ ).

In another randomized trial, 192 women undergoing CD for obstructed labor were randomly assigned to reverse breech extraction or pushing the head up with a hand in the vagina. ${ }^{3}$ Compared with the vaginal push technique, reverse breech extraction was associated with fewer extensions of the uterine incision ( $19 \%$ vs $48 \%$; $P=.003$ ), fewer cases of wound infection (2\% vs $13 \%$; $P=.007)$, and fewer blood transfusions (2 vs $11 ; P=.012$ ).

Additional options and adjuvants 
FIGURE 1 Pushing up the fetal head with a vaginal hand

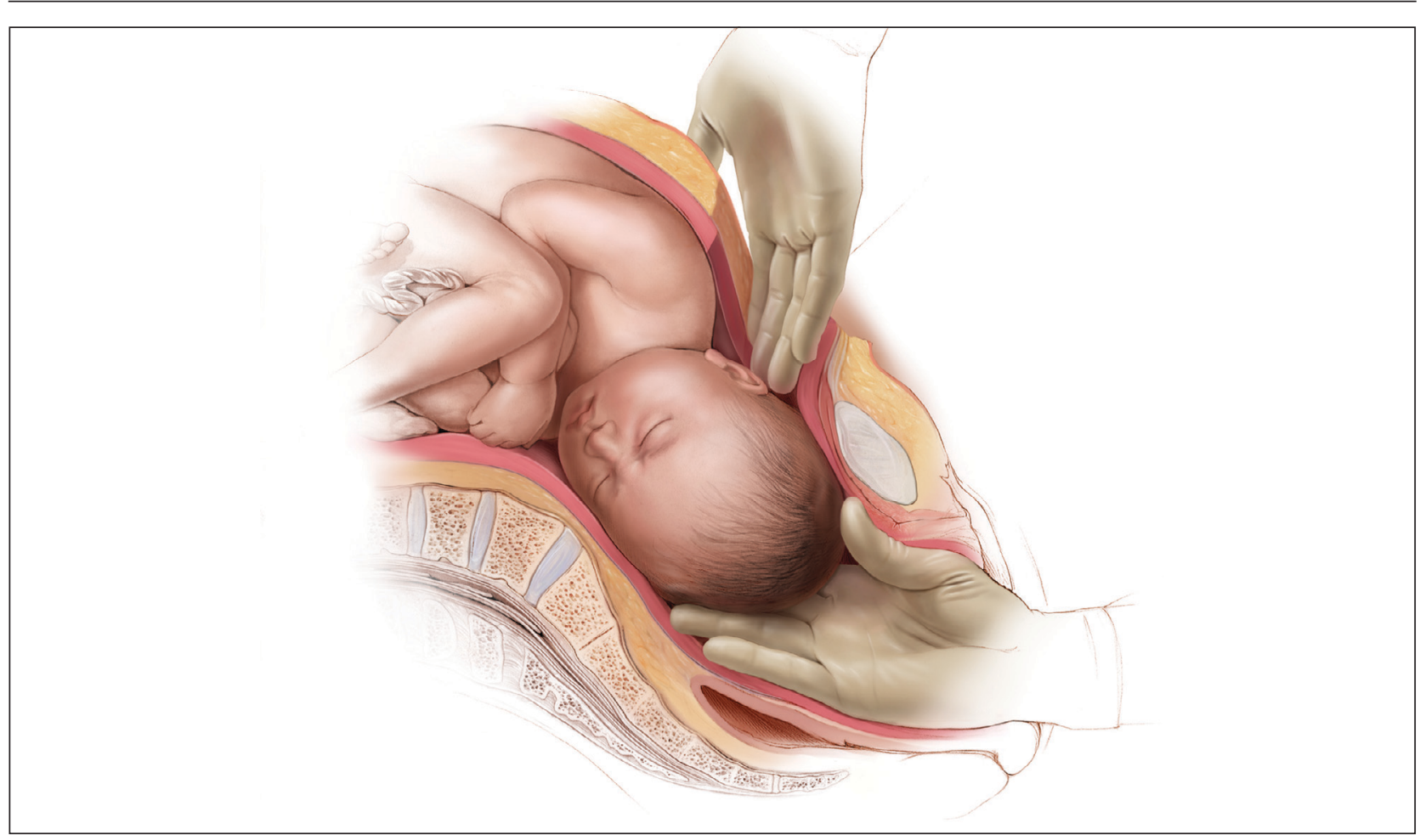

FIGURE 2 Reverse breech extraction

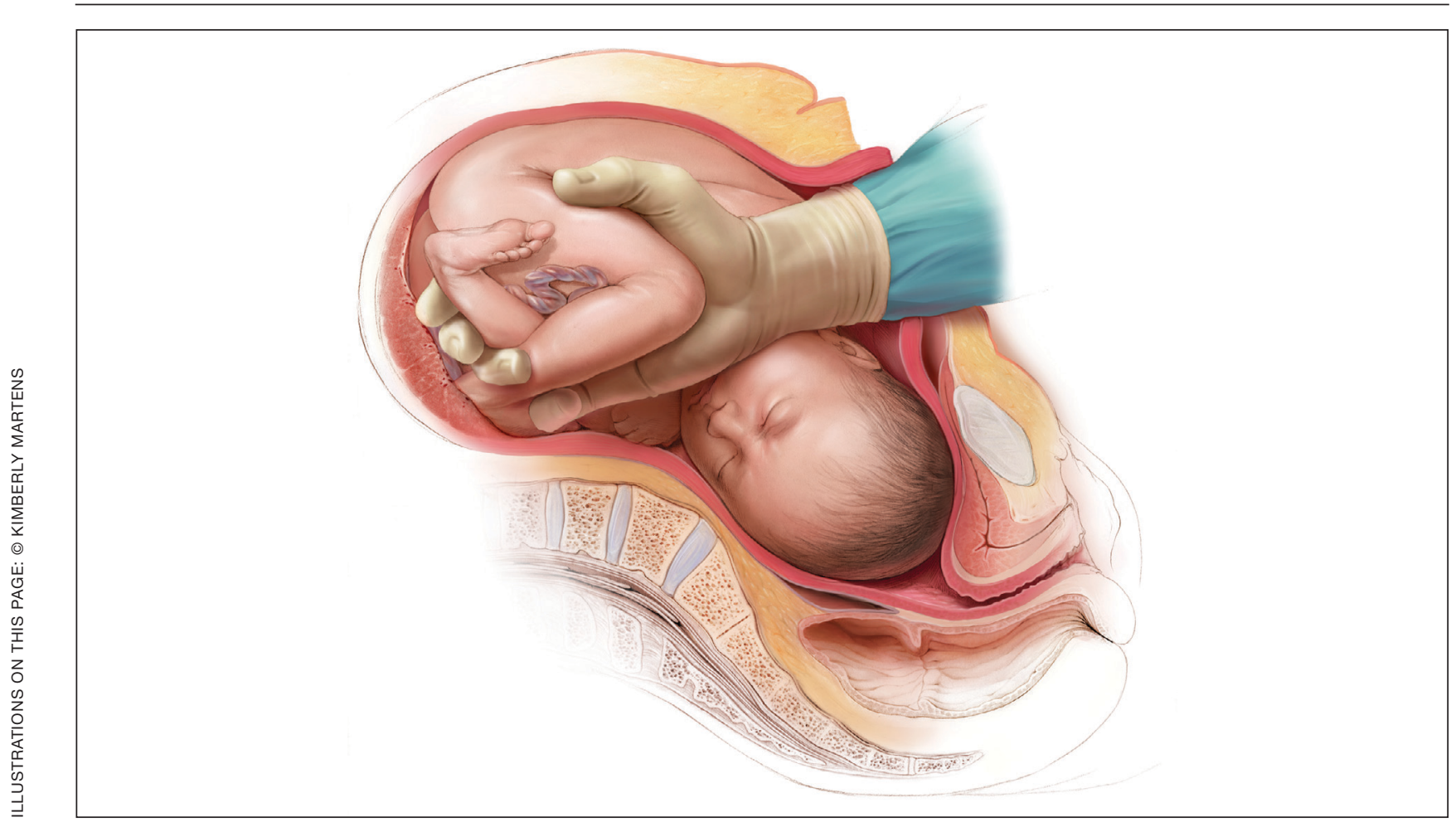


Figure 3 Fetal Pillow

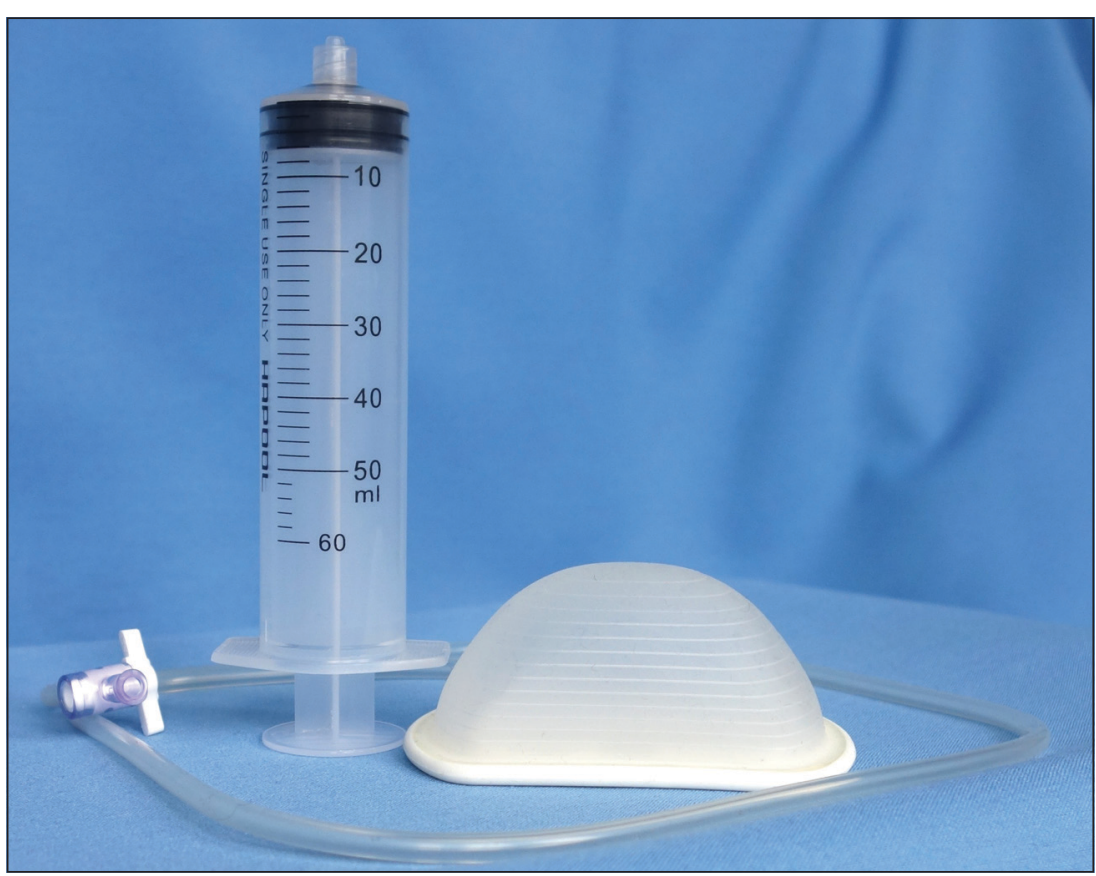

for facilitating delivery of a fetal head deeply impacted in the pelvis include: using a Coyne spoon, using nitroglycerine or terbutaline to relax the myometrium, breaking the vaginal suction on the fetal head before attempting delivery, keeping the wrist of the delivering hand as straight as possible to reduce uterine incision extensions, and incising the ring (if a Bandl's ring is detected).

\section{The Fetal Pillow}

The Fetal Pillow (Safe Obstetric Systems, New York, New York) is a single-use fetal cephalic elevation device for managing the deeply impacted fetal head (FIGURE 3). The Fetal Pillow has a firm plastic base upon which is attached a soft silicon balloon. The Fetal Pillow is inserted into the vagina prior to initiating $\mathrm{CD}$ and the balloon is filled with $180 \mathrm{~mL}$ of saline, causing the fetal head to be pushed to a higher station (FIGURE 4). Use of the Fetal Pillow may be indicated prior to $\mathrm{CD}$ in the following situations:

- second stage labor with a deeply impacted head

- second stage labor and failed operative delivery

- occiput posterior position or deep transverse arrest

- absent progress in the first stage between $8 \mathrm{~cm}$ and $10 \mathrm{~cm}$ with a deeply impacted fetal head or excessive caput of the fetal head.

The Fetal Pillow is inserted after completing vaginal preparation for $\mathrm{CD}$ and before initiating skin preparation and abdominal draping. The steps for inserting the Fetal Pillow include:

1. Use the $60 \mathrm{~mL}$ syringe to fully deflate the Fetal Pillow and leave the cock-stop open.

2. Fold the Fetal Pillow by squeezing the firm plastic base, and with the patient's legs in a frog-leg position, place the device in the vagina.

3. Allow the firm plastic base to open to a flat position with the base against the posterior vaginal wall and the soft silicon balloon against the fetal head.

4. Using pressure on the plastic base, gently push the Fetal Pillow posteriorly toward the sacrum of the mother.

5. Use the $60 \mathrm{~mL}$ syringe to inflate the balloon with $180 \mathrm{~mL}$ of normal saline and close the valve.

6. Straighten the patient's legs and proceed with skin preparation and abdominal draping (FIGURE 4).

When the CD is completed, deflate the balloon by drawing out the saline with the $60 \mathrm{~mL}$ syringe and remove the device by hooking a finger around the firm plastic base. The Fetal Pillow is surprisingly easy to use.

\section{Effectiveness of the Fetal Pillow}

In one randomized trial, 240 women undergoing CD were randomly allocated to a group in which the Fetal Pillow was placed in the vagina and inflated prior to the cesarean and a control group in which the Fetal Pillow was not used. In this study the mean length of the second stage averaged 1.9 hours. ${ }^{4}$ Compared with no Fetal Pillow, use of the Fetal Pillow was associated with a reduction in grade 3 extension of the uterine incision (extension into the uterine artery, vagina, or bladder) (2.5\% vs $23 \%)$, a reduction in blood loss > 1,000 $\mathrm{mL}$ ( $4 \%$ vs $22 \%$ ), and fewer difficult plus very difficult deliveries of the fetal head as reported by the surgeon ( $6 \%$ vs $39 \%$ ).

In another randomized trial, 60 nulliparous women undergoing $\mathrm{CD}$ in the second stage of labor had a Fetal Pillow inserted in the vagina and were randomly allocated to inflation of the pillow (Fetal Pillow group) or noninflation of the pillow 


\section{Figure 4 Placement of the Fetal Pillow}

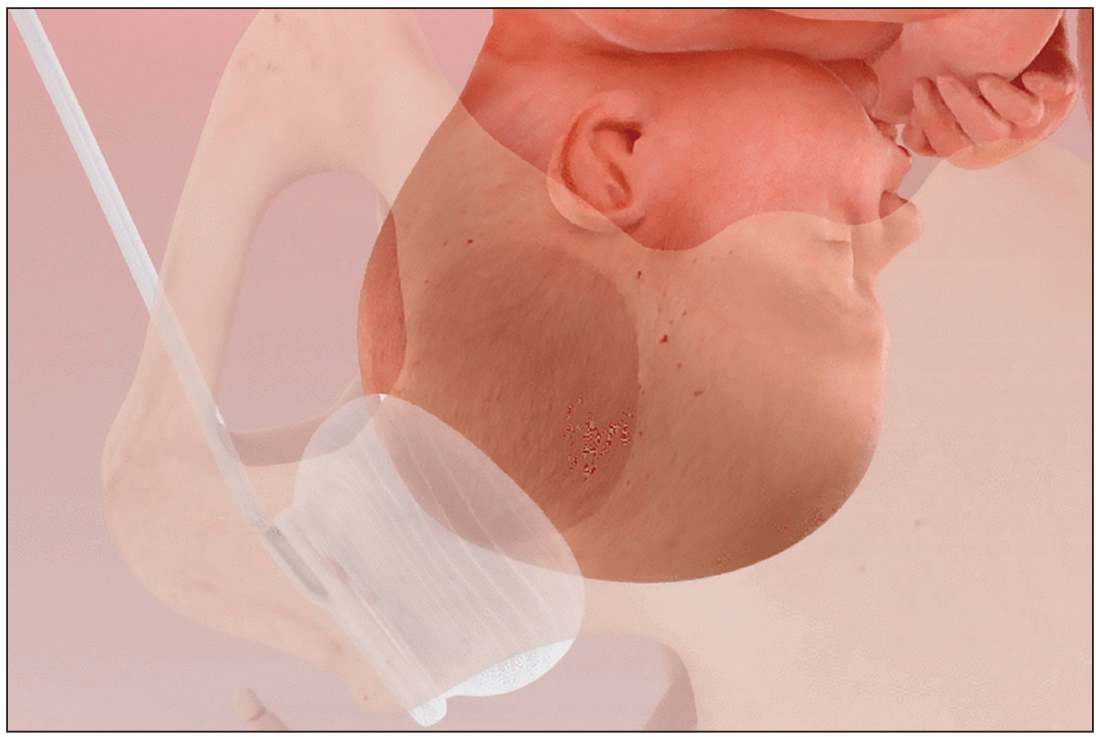

(control group). ${ }^{5}$ In this study the mean length of the second stage was 4 hours. Compared with noninflation of the Fetal Pillow, use of the inflated Fetal Pillow was associated with a reduction in grade 3 extension of the uterine incision (extensions into the uterine artery, vagina, or bladder) ( $0 \%$ for inflation vs $13 \%$ for noninflation) and fewer difficult plus very difficult deliveries of the fetal head as reported by the surgeon ( $0 \%$ for inflation vs $37 \%$ for noninflation). There was no significant difference in blood loss between the two groups ( $800 \mathrm{~mL}$ vs $900 \mathrm{~mL}$ ). These two randomized studies both reported that the use of the Fetal Pillow was associated with a reduction in grade 3 extensions of the uterine incision and a decrease in the difficulty of delivering the fetal head.

\section{Consider trialing the Fetal Pillow}

When a CD is performed after a prolonged second stage of labor, surgical complications are common, including extensions of the uterine incision and difficulty delivering the fetal head. When a grade 3 extension occurswith tearing of a uterine artery, deep extension into the vagina, or damage to the bladder-the surgical repair can be extraordinarily challenging. Clinical trials report that both reverse breech extraction and the Fetal Pillow can facilitate $\mathrm{CD}$ in the setting of a prolonged second stage. For many obstetricians reverse breech extraction is a challenging obstetric maneuver. The insertion and inflation of a Fetal Pillow is a simple procedure. Obstetrician-gynecologists learn by doing. If you have never used the Fetal Pillow, I suggest you consider trialing it in your practice.

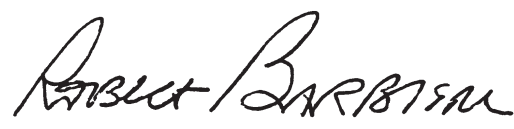

RBARBIERI@MDEDGE.COM

Dr. Barbieri reports no financial relationships relevant to this article.

\section{References}

1. Jeve YB, Navti OB, Konje JC. Comparison of techniques used to deliver a deeply impacted fetal head at full dilation: a systematic review and meta-analysis. BJOG. 2016;123:337-345.

2. Fasubaa OB, Ezechi OC, Orji EO, et al. Delivery of the impacted head of the fetus at cesarean section after prolonged obstructed labor: a randomised comparative study of two methods. J Obstet Gynaecol. 2002;22:375-378.

3. Nooh AM, Abdeldayem HM, Ben-Affan O. Reverse breech extraction versus the standard approach of pushing the impacted fetal head up through the vagina in caesarean section for obstructed labour: a randomised controlled trial. J Obstet Gynaecol. 2017;37:459-463.

4. Seal SL, Dey A, Barman SC, et al. Randomized controlled trial of elevation of the fetal head with a fetal pillow during cesarean delivery at full cervical dilatation. Int J Gynaecol Obstet. 2016;133:178-182.

5. Lassey SC, Little SE, Saadeh M,et al. Cephalic elevation device for second-stage cesarean delivery: a randomized controlled trial. Obstet Gynecol. 2020;135: 879-884. 